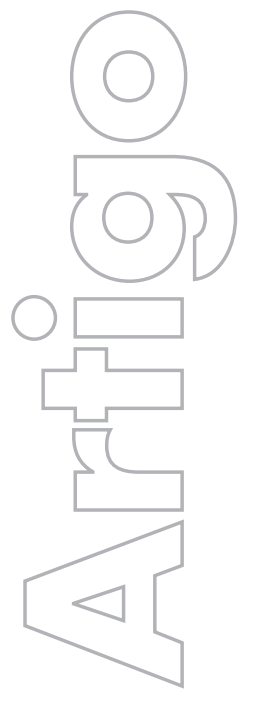

revista

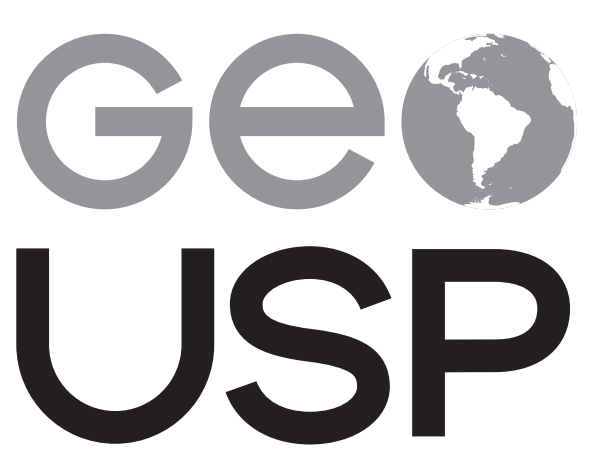

espaço e tempo

Volume $20 \cdot n^{\circ} 2(2016)$

ISSN 2179-0892

\section{A produção social do espaço e a relação} cidade-rio na ribeira de Marabá-PA: modernização, conflitos e resistências

\author{
Michel de Melo Lima \\ NAEA-UFPA
}

p. $267-280$

Como citar este artigo:

LIMA, M. M. A produção social do espaço e a relação cidade-rio na ribeira de Marabá-PA: modernização, conflitos e resistências. Geousp - Espaço e Tempo (Online), v. 20, n. 2, p. 267-280, mês. 2016. ISSN 2179-0892.

Disponível em: <http://www.revistas.usp.br/geousp/issue/ view/6465>. doi: http://dx.doi.org/10.11606/issn.2179-0892. geousp.2014.84539.

\section{(c) $(1) \circledast$}

Este artigo está licenciado sob a Creative Commons Attribution 4.0 License. 


\title{
A produção social do espaço e a relação cidade-rio na ribeira de Marabá-PA: modernização, conflitos e resistências
}

\section{Resumo}

Este artigo discute a relação cidade-rio na Amazônia a partir de um estudo de caso: o processo de modernização da orla fluvial da cidade de Marabá. Analisa a produção social do espaço, os conflitos de territorialidades e a resistência à dinâmica regional da recente modernização capitalista da Amazônia e de Marabá, levando em conta as especificidades locais da relação/interação econômica, funcional e simbólico-cultural dos diferentes agentes/grupos com os rios Tocantins e Itacaiunas. Mostra que, mesmo diante dos processos modernizantes previstos e executados (construção do calçadão, do cais de arrimo, de pontes, vias, portos, hidrelétrica etc.) na cidade, permanece residualmente o modo de vida ribeirinho em sua orla fluvial, principalmente nos espaços de identidade e de vivência ribeirinha.

Palavras-chave: Relação cidade-rio. Orla fluvial. Modernização. Espaço vivido. Resistência.

The production of the space and the relationship city-river in the ribeira of Maraba-PA: modernization, conflicts and resistances

\begin{abstract}
The reflections of this study are in line with the theme: the relationship city-river in the Amazon developed through of a case study, the process of modernization of Maraba's waterfront. The objective is to analyse the social production of space, the conflicts of territoriality and the resistances to the recente regional dynamics of capitalist modernization of the Amazon and Maraba, taking into account local specificities of the economic, functional, and symbolic-cultural relationship/interaction among different agents/groups with the Tocantins and Itacaiunas rivers. This article shows that was found a residual permanence of the riverine way of life in waterfront of Maraba, mainly through of the spaces of riverine identity and riverine living, in spite of the modernization processes executed and planned (construction of the boardwalk, retaining pier, bridges, roads, ports, hydroelectric etc.) for this city.
\end{abstract}

Keywords: Relationship city-river. Waterfront. Modernization. Lived space. Resistance. 


\section{Introdução}

Os primeiros aglomerados populacionais existentes na Amazônia, embriões de parte de seus atuais núcleos urbanos, surgiram ao longo dos rios. Isso ocorreu pela importância da localização beira-rio e das águas, tanto no que diz respeito à posição estratégica e ao processo de defesa da coroa portuguesa contra invasores, quanto por serem elementos essenciais que possibilitaram o início da circulação de fluxos regionais (pessoas, mercadorias informações) (Trindade Jr.; Amaral; Silva, 2008).

É em face desse contexto que se destaca o fato de grande parte desses aglomerados, vilas, povoados e cidades amazônicas apresentarem íntima relação e interação, funcional e simbólico-cultural, com a floresta e com os rios. Tal cenário levou Tocantins (1961) a afirmar que a natureza, apesar do lento e contínuo esforço para humanizá-la, absorvia e envolvia o homem em suas malhas. Daí o(s) rio(s), uma das mais poderosas forças do meio, "dominar/ comandar" a vida, que, até a década de 1950, era profundamente marcada por "fatores geográficos" (naturais).

Embora o conteúdo dessa perspectiva seja notadamente determinista, ela serve para mostrar o quanto a vida na Amazônia esteve ligada aos rios e à floresta. Assim, entender a forma da relação cidade-rio frente aos novos processos de exploração dos recursos naturais oriundos da intensificação da inserção da Amazônia brasileira na economia nacional e internacional após a década de 1960 implica uma análise fundamental para compreender a diversidade de manifestações do fenômeno urbano na região (Trindade Jr., 2010).

É nesse contexto que a cidade de Marabá-PA, cuja atual dinâmica socioespacial está intimamente associada ao processo de modernização capitalista recente da Amazônia (exploração mineral por meio de grandes projetos, agropecuária, circulação rodoferroviária etc.), e seu espaço de orla fluvial, que está ligado aos rios (Tocantins e Itacaiunas) e a uma temporalidade ribeirinha do passado, emergem como recorte analítico de estudo, pois permitem entender a articulação desses diferentes tempos, territorialidades e ritmos sociais na Amazônia brasileira.

O presente trabalho analisa a produção social do espaço, os conflitos de territorialidade existentes na orla fluvial de Marabá e as resistências à dinâmica regional recente de modernização capitalista da Amazônia; resistências essas expressas por meio da permanência residual (Nasser; Fumagalli, 1996) de espaços de identidade e de vivências ribeirinhas na orla da cidade de Marabá.

Com efeito, na primeira seção serão abordados os elementos referentes ao marco teórico que instrumentalizou a análise. Além disso, também será apresentado o recorte analítico de estudo, a orla fluvial da cidade de Marabá. Sua proposta é dar subsídios teórico-metodológicos, com discussão da relação cidade-rio do ponto de vista abstrato e apresentar a orla fluvial da cidade de Marabá, de maneira concreta, como forma de apontar elementos pertinentes para a melhor compreensão do tema referente às cidades amazônicas e à relação cidade-rio em âmbito regional.

A primeira seção consistirá em um ponto inicial para, no segundo momento, realizar-se uma retomada histórica e geográfica do processo de produção do espaço da cidade de Marabá e de sua orla fluvial, no intuito de entender como se desenvolveu a relação cidade-rio ao longo do tempo. 
Na terceira seção, serão apresentados os espaços de identidade e de vivência ribeirinha (Silva; Malheiro, 2005) da cidade de Marabá-PA. O objetivo é demonstrar que a dimensão do vivido ligada aos rios e à floresta não desapareceu em face da ascensão do percebido e do concebido associados à lógica de modernização capitalista, mas sim se perpetuou na ribeira marabaense por meio da formação de espaços de resistência e de disseminação/difusão de conteúdos socioespaciais ribeirinhos (Lima, 2013).

Por fim, é importante destacar que, procurando dar voz e vez ao homem (e à mulher) comum, que em Marabá sobrevive nos espaços de identidade e vivência ribeirinha e tem um importante referencial de vida nas águas do Tocantins e do Itacaiunas e mesmo na floresta, esse texto pretende concorrer para reconhecer seu protagonismo social e subsidiar políticas públicas mais alinhadas com as especificidades urbanas da orla fluvial de Marabá.

\section{A produção social do espaço na orla fluvial da cidade de Marabá-PA}

O processo de produção social do espaço na orla fluvial de Marabá, uma cidade localizada no sudeste do Pará, está intimamente ligado ao surgimento dessa urbe, que teve sua ocupação inicial localizada no pontal, na confluência dos rios Tocantins e Itacaiunas. Esses rios, por possibilitarem o início da circulação de mercadorias, produtos (caucho, castanha), informações e pessoas, foram fundamentais para a formação do aglomerado populacional que originou Marabá (Velho, 1972).

Além disso, atualmente, podem-se considerar suas águas importantes para o desenvolvimento de dinâmicas socioespaciais na orla fluvial marabaense, principalmente para os agentes/grupos que cotidianamente desenvolvem práticas ribeirinhas, como a utilização dos rios para a obtenção de recursos (água e pescado), como meio de circulação (transporte fluvial) e como referencial simbólico e cultural (identificação dos agentes com o tempo lento do rio e da floresta) (Lima, 2013).

A faixa de orla da cidade de Marabá se encontra nos espaços de contato entre a terra (cidade) e as águas (rios Tocantins e Itacaiunas). Por isso, abrange parte dos mais importantes núcleos urbanos de Marabá, quais sejam: o núcleo Marabá Pioneira, o núcleo Cidade Nova, o núcleo Nova Marabá e o núcleo São Félix. Destaca-se, também, que foi incluída na análise a comunidade de pescadores da vila Espírito Santo, uma localidade que não faz parte direta do tecido urbano da cidade, mas que por este é influenciado e será diretamente impactada pela construção de um importante empreendimento, a Usina Hidrelétrica de Marabá. Além disso, frisa-se que, ao longo da orla, são encontrados os espaços de identidade e de vivência ribeirinha da cidade, isto é, resíduos (Nasser; Fumagalli, 1996) cuja dinâmica socioespacial espelha o viver ribeirinho de outrora (Mapa 1).

\footnotetext{
1 De modo geral, orla é o espaço imediato de interação entre terra e a água, independentemente do tamanho do rio. Entretanto, para efeito de análise, consideramos orla a faixa que margeia os principais corpos hídricos de uma cidade (Trindade Jr.; Santos; Ravena, 2005); no caso de Marabá, os rios Tocantins e Itacaiunas. Isso se deve ao fato de os usos e as práticas socioespaciais ali desenvolvidas terem contato, dependência e interação, material ou simbólica mais intensa e regular com esses rios (Lima, 2013).
} 


\section{Mapa 1 - Orla da cidade de Marabá e seus espaços de identidade e vivên- cia ribeirinha}

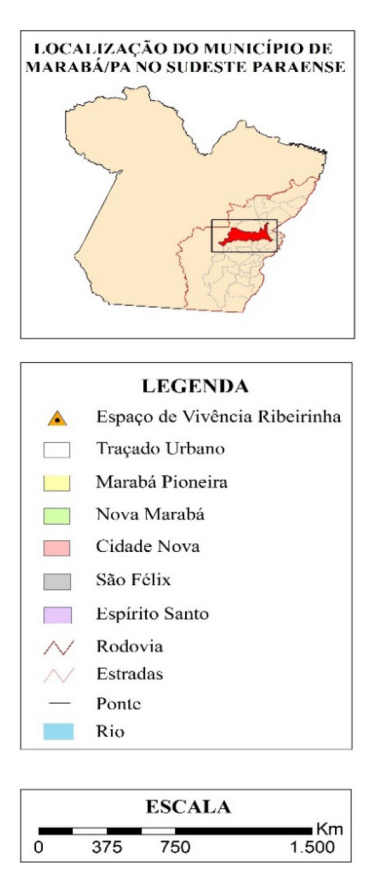

Fonte: PNM, Autora: PMM, Dorar Aquinin Numcs
Data: 14 de fevcreriro de 2013

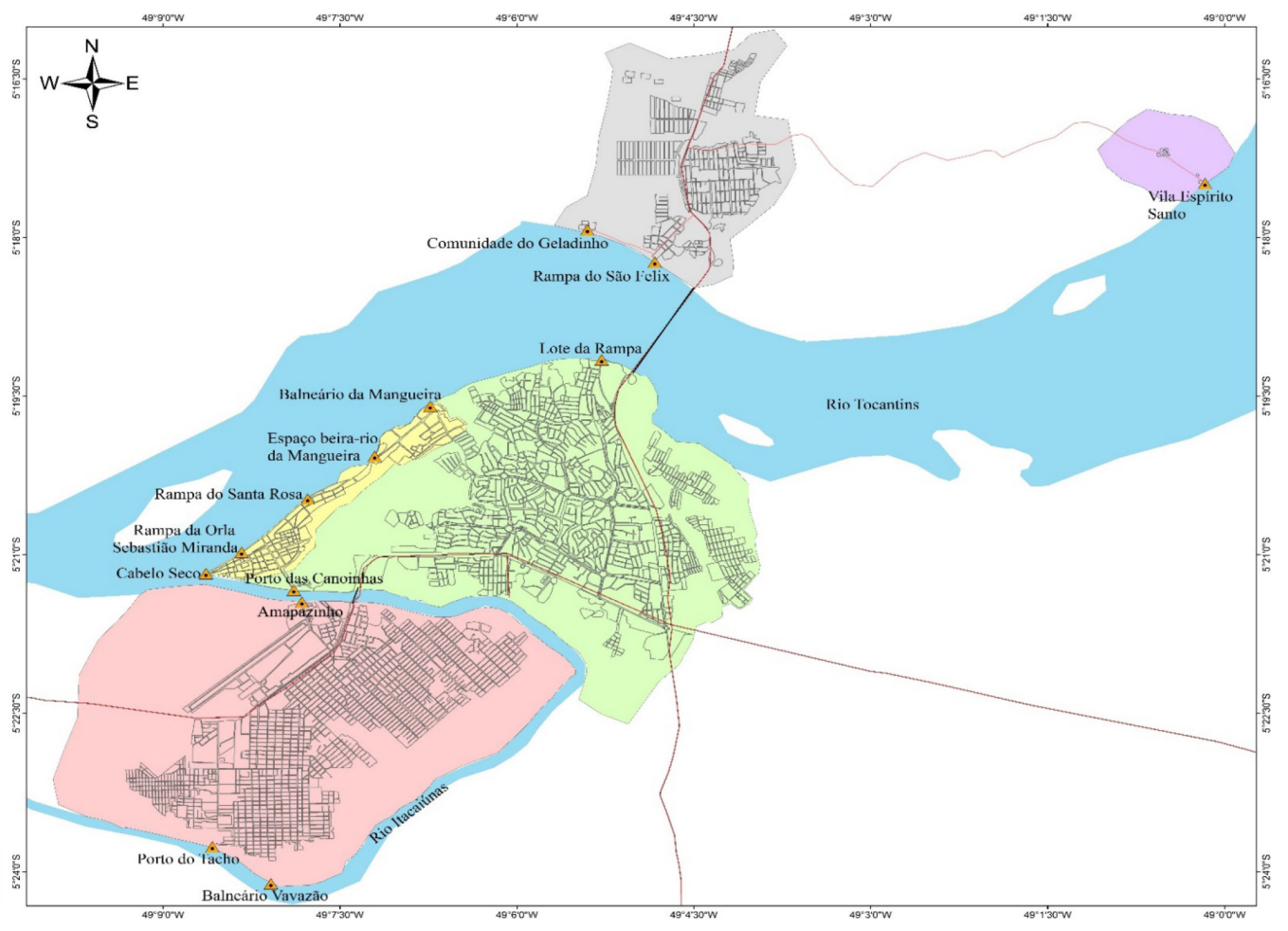

Por outro lado, atualmente, atribuir à orla da cidade apenas a característica de espaço que espelha um "mundo das águas" é insuficiente para entender a complexidade e a multiplicidade de suas dinâmicas sociais (espacialidades e temporalidades). Isso porque, após a realização de melhorias infraestruturais na frente fluvial da cidade, que tiveram início da década de 2000, boa parte dessa ribeira ${ }^{2}$ tornou-se a principal alternativa de lazer e turismo em Marabá (Lima, 2013).

$\bigcirc$ projeto de melhorias infraestruturais, que se iniciou com uma parceria entre o governo municipal e o governo federal, prevê várias ações: a construção de um muro de arrimo para conter as águas das enchentes, a pavimentação de ruas, a realização de melhorias habitacionais (esgoto sanitário e abastecimento de água), a regularização fundiária, a construção de áreas de lazer e a construção de 80 novos imóveis para beneficiar famílias que moram na área mais propensa a enchentes (Marin; Trindade, 2009). Mesmo inacabadas, essas obras já transformaram esse espaço em área "nobre", disputada por visitantes, turistas e toda a população da cidade, tanto pelas amenidades naturais relativas aos rios como pela concentração de usos ligados a entretenimento, lazer e turismo (Marabá, 2006).

Ademais, também estão previstas outras grandes intervenções: (a) implantação de um porto na margem esquerda do rio Tocantins para dar suporte às atividades siderúrgicas do empreendimento Aços Laminados do Pará (Alpa), o que também transformará a orla em espaço de escoamento

2 ○ termo ribeira, aqui sinônimo de orla, designa também a faixa imediata de contato/interação entre a terra e a água de Marabá. Mais comumente associado aos espaços de frentes fluviais das pequenas e médias cidades amazônicas, ele se refere a lugares com usos e práticas socioespaciais cotidianas ligadas ao tempo lento do rio e da floresta, de forma múltipla (econômica, funcional e simbólico-cultural) e em diferentes escalas. 
de produtos industrializados (Marin; Trindade, 2009); (b) construção da Usina Hidrelétrica de Marabá; e (c) implantação da Hidrovia Araguaia-Tocantins. Sendo de grande porte, essas intervenções imprimirão mudanças profundas na morfologia material e social dessa ribeira, estando portanto associadas ao modelo de urbanização empreendedor e mercadológico que nela se desenvolve.

Para entender esse processo, é fundamental destacar que no modo de produção capitalista, o espaço inteiro e em toda a sua complexidade é tomado por esta racionalidade mercadológica (ou pelo menos ela tenta tomá-lo, dominá-lo, subjugá-lo). Assim, ele é usado para produzir mais-valia, de modo que a terra, o subsolo, o ar entram nas forças produtivas e nos produtos como mercadoria. $\bigcirc$ tecido urbano, aquele das redes múltiplas de comunicação e de trocas, acaba, então, fazendo parte dos meios de produção. A cidade e suas diversas instalações (correios, estradas de ferro, depósitos e entrepostos, transportes de serviços diversos etc.) são capital fixo. A divisão do trabalho penetra o espaço inteiro (e não apenas o espaço do trabalho, aquele das empresas ou das indústrias). Assim, o espaço é "consumido" do mesmo modo que os edifícios e os locais industriais, as máquinas, as matérias-primas e a própria força de trabalho (Lefebvre, 1974).

Esse processo que ocorre nas frentes marítimas e fluviais, principalmente de cidades de importância regional (como Marabá), nacional e internacional, pode ser associado ao que Harvey (2005) denominou empreendedorismo urbano, que seria o processo de amoldamento/ adequação dos espaços das cidades às necessidades do mercado e do capital no atual contexto de globalização.

Portanto, na orla de Marabá se rebatem formas de apropriação do espaço diferenciadas e/ou conflituosas. A primeira, mais antiga e de origem ribeirinha; e a segunda, mais recente e ligada ao processo de apropriação capitalista do espaço das cidades. Em face desse contexto, pode-se afirmar que, numa urbe como Marabá, cuja origem está intimamente ligada às águas dos rios Tocantins e Itacaiunas, o espaço socialmente produzido se desenvolve por meio de todas as racionalidades e modos de apropriação existentes; os que são influenciados por uma ordem distante (moderna e capitalista) e por uma ordem próxima (Lefebvre, 2006), que está associada aos rios e à dinâmica da natureza (Lima, 2013).

\section{A relação cidade-rio na orla fluvial de Marabá: mudanças, permanências e conflitos}

A origem da cidade de Marabá está ligada ao contexto do espaço regional amazônico durante o século XIX, período em que desponta a atividade econômica ligada ao extrativismo da goma elástica da borracha (hevea brasilienses). $O$ crescimento econômico e demográfico proporcionado pela atividade extrativista da borracha demandou a expansão da produção agrícola e da pecuária para atender às necessidades alimentares da capital do estado, Belém. É nesse contexto que, na sub-região do sudeste paraense se dá a fundação, por Carlos Gomes Leitão, no ano de 1895, do Burgo Agrícola do Itacaiunas, a 8 quilômetros da foz do rio Itacaiunas (Velho, 1972).

A criação do burgo teve como consequência o início do povoamento no sudeste paraense, uma vez que se estabeleceram familias, casas e, aos poucos, desenvolveram-se povoados na margem esquerda do Tocantins. No entanto, as dificuldades pelas quais passaram o burgo (insalubridade do sítio) e a descoberta do caucho, um tipo de goma elástica provinda da castanheira (hevea castilhoa), consistem em fatores que contribuíram decisivamente para o seu despovoamento e para a sua desagregação (Emmi, 1999). 
Nesse contexto, por vantagens locacionais como a facilidade de circulação e comunicação por meio das vias fluviais, os caucheiros e comerciantes (responsáveis por fornecer, pelo sistema de aviamento, as mercadorias necessárias ao internato na mata) concentraram-se na ponta de terra situada na confluência dos rios Tocantins e Itacaiunas (Emmi, 1999). É nesse espaço que se forma, em 7 de julho de 1898, o aglomerado que daria origem à cidade de Marabá (Velho, 1972), começando efetivamente a ocupação de sua orla com a formação do Cabelo Seco, atual bairro Francisco Coelho, um dos principais espaços de identidade e vivência ribeirinha na cidade.

A Marabá desse período apresentava aspecto urbano precário, característica que contrastava com a riqueza e esplendor da borracha. Entretanto, sua importância econômica crescente fez com que, posteriormente, mais afastadas da beira-rio surgissem casas melhores e aos poucos se configurasse uma pequena cidade ${ }^{3}$ (Velho, 1972).

A queda da demanda da borracha no mercado europeu e a consequente estagnação econômica regional, processo que tem início na década de 1920 (Corrêa, 1987), fez com que as atividades ligadas à exploração da castanha e de seu fruto (ouriço) ganhassem destaque. Por conta disso, a cidade de Marabá tornou-se um dos principais pontos de comercialização desse produto e um importante entreposto comercial no médio Tocantins (Velho, 1972).

Marabá cresceu no sentido da montante dos rios Tocantins e Itacaiunas. $\bigcirc$ traçado das ruas principais acompanhava os rios, pelas facilidades e vantagens econômicas da topografia do sítio. Ademais, a margem do Tocantins ganhou importância pelo estabelecimento das principais casas comerciais e armazéns de depósito de castanha na época (Dias, 1958).

No fim de década de 1930, começou a se desenvolver na cidade uma frente mineradora ligada à extração de cristal de rocha e diamantes; atividade cuja coleta era feita no fundo dos rios durante o período de seca. Essa frente mineradora acabou por se tornar complementar à castanha e levou à fixação permanente da população na cidade (Velho, 1972; Dias, 1958).

É importante ressaltar que até o final da década de 1950, o crescimento da cidade ainda se dava predominantemente acompanhando os rios Tocantins e Itacaiunas. Tal contexto, somado ao uso e a interação dos grupos sociais com estes corpos hídricos, confirmava a existência de uma temporalidade e/ou vivência ribeirinha ao longo do espaço de orla da cidade.

Por outro lado, após a década de 1960, intensifica-se a incorporação da Amazônia brasileira à economia nacional e global, principalmente pela ação do Estado e de empresas que exploram os recursos naturais da região. Um período que se destaca principalmente pela presença de uma racionalidade capitalista, perpetuada por incentivos fiscais do Estado nacional e pela criação da infraestrutura necessária para as empresas desenvolverem suas atividades. Além disso, ressalta-se, nesse contexto, a inserção das rodovias como novos eixos de circulação regional (Corrêa, 1987; Rocha, 2008).

É nesse momento que a cidade de Marabá, muito conhecida por atividades relativas à extração de castanha, cristal de rocha e diamantes, bem como por sua ligação com os rios, sofreu mudanças significativas em sua morfologia material e social.

A abertura de estradas e rodovias (a exemplo da Transamazônica) acentuou a ocupação e o adensamento populacional do sudeste paraense (Mattos, 1996). Além disso, destacam-se: a desco-

3 O município de Marabá foi criado em 1913. Em 1922, o município de São João do Araguaia foi extinto, e seu território foi anexado ao de Marabá, que, já em 27 de outubro de 1923, foi elevado à categoria de cidade, por sua importância comercial (Dias, 1958). 
berta do potencial mineral da área - Serra das Primeiras Descobertas Carajás, ${ }^{4}$ cujo minério era explorado pela Companhia Vale do Rio Doce (CVRD); a construção da Usina Hidrelétrica de Tucuruí, em 1984, para dar suporte energético à implantação de projetos como Albras/Alunorte e Carajás (Rocha, 2008); a criação de um novo núcleo "planejado" denominado Nova Marabá, que tinha seu modelo urbanístico com o traçado no formato de uma castanheira e que visava edificar uma nova área para as pessoas atingidas pela enchente anual, muito embora diversos autores afirmem que seu real objetivo fosse criar moradias para abrigar grande parte da corrente migratória gerada pela exploração do ouro do garimpo de Serra Pelada, bem como ser o centro de apoio aos grandes projetos que estavam em desenvolvimento (Yoschioka, 1986; Almeida, 2008); e o projeto de assentamento do Incra, que objetivava assentar os colonos, sobretudo do Nordeste, nas terras disponibilizadas às margens das rodovias federais em fase de implantação, inclusive na Transamazônica (Almeida, 2008).

Para a análise da relação cidade-rio e da dimensão ribeirinha em Marabá, também é importante destacar a construção, em 1981, da ponte sobre o rio Itacaiunas, que ligaria diretamente o núcleo Nova Marabá ao núcleo Cidade Nova; e a construção, em 1984, da ponte mista (rodoferroviária) de Marabá, sobre o rio Tocantins. A construção das pontes sobre esses rios diminuiu significativamente a importância do transporte fluvial local, principalmente após a desativação das rampas onde atracavam balsas que faziam o transporte de pessoas, veículos e mercadorias na cidade (Lima, 2013).

Assim, fatores como a diversificação produtiva da cidade, que nesse contexto tinha a sua base assentada na agropecuária, na indústria minerometalúrgica e no extrativismo vegetal e mineral (Tavares, 1999), a importância política e regional adquirida - ascensão de Marabá ao nível de cidade média (Trindade Jr., 2011) - e a chegada de grandes agentes/grupos econômicos à cidade (a exemplo da Vale) fazem com que o espaço de orla desponte como local "estratégico" e de grande potencial para a geração de riquezas para o poder público e para os demais agentes/grupos que nele tem um referencial predominantemente econômico.

É nesse contexto que ocorrem as já mencionadas melhorias no waterfront fluvial da cidade, como a construção de um muro de arrimo para conter as águas das enchentes, a pavimentação de ruas, a realização de melhorias habitacionais como esgoto sanitário e abastecimento de água, a regularização fundiária etc. (Marin; Trindade, 2009).

Os lugares onde foram realizadas essas obras estão mais valorizados e são disputados por visitantes e pela população de toda a cidade, principalmente pela vista que oferecem dos rios e pela concentração de usos ligados a entretenimento, lazer e alternativas de alimentação. Além disso, atualmente estão previstas diversas intervenções/obras para a ribeira de Marabá, são elas: (a) a construção de um porto que dará suporte as atividades siderúrgicas da Alpa, o que transformará a orla em espaço de escoamento de diversos produtos, inclusive industrializados; (b) a edificação da Hidrelétrica de Marabá, um empreendimento que tem por objetivo atender as demandas locais e regionais de energia; (c) a implantação da Hidrovia Araguaia-Tocantins, que visa ao surgimento de um novo eixo centro-norte de transporte fluvial, com ênfase na circulação das mais variadas cargas, principalmente commodities. Tais obras/intervenções são reivindicadas pela administração pública municipal de Marabá e por grande parte dos agentes/grupos empreendedores locais e regionais (Lima, 2013).

4 Para transportar minério da Serra dos Carajás até o litoral, onde era embarcado para outros países, a CVRD construiu a Estrada de Ferro Carajás, que entrou em funcionamento em 1984, com 85 quilômetros de extensão. A ferrovia atravessa o rio Tocantins na altura de São Félix (um núcleo de Marabá), onde foi construída uma ponte rodoferroviária (Mattos, 1996). 
É por entre estas territorialidades múltiplas, (co)existentes e conflitantes que se desenvolve, então, a relação cidade-rio em Marabá e em sua ribeira; ${ }^{5}$ espaço que foi alvo de diferentes formas de dominação/apropriação/uso ao longo do tempo, que estão associadas, respectivamente, tanto ao início da circulação regional e a utilização dos rios e da floresta, principalmente, como recurso e referencial de vida, quanto ao processo de modernização capitalista do espaço da Amazônia no período recente.

Desse modo, o processo de aproveitamento capitalista da orla de Marabá acabou, em grande parte, por privilegiar a inserção de formas mais modernas e a intensificação dos fluxos de capitais mais dinâmicos nessa ribeira. Por conta disso, negou características próprias da produção do espaço de orla, como a sua ligação/interação com os rios Tocantins e Itacaiunas e a floresta. Uma negação que gera conflitos de territorialidade, barulhentos e silenciosos, associados à transformação dos principais espaços de contato imediato entre a terra e a água - os referenciais de vida de grande parte da população que mora na orla de Marabá - em locais de realização de negócios. Isto é, do "novo" (moderno e capitalista) que exclui o "velho" (a dimensão e vivência ribeirinha existente) (Lima, 2013).

\section{O percebido, o concebido e o vivido: o direito à cidade como possibilidade do reconhecimento da dimensão ribeirinha da cidade de Marabá}

As seções anteriores deste trabalho mostraram como o processo de modernização que atualmente ocorre na orla fluvial de Marabá está associado a um modelo hegemônico de sociedade que busca inserir os espaços urbanos de forma mais direta e indireta na acumulação de capital.

Por outro lado, embora pareça negar a ligação multidimensional (econômica em diversas escalas, funcional e simbólico-cultural) de Marabá com rios, esse contexto não impede a formação de espaços de resistência a esse processo mercadófilo e modernizante. Eé justamente sobre esses espaços, cujo vivido ribeirinho subverte a ascensão do concebido e do percebido moderno, que trata a última seção deste trabalho.

O processo empreendedor-modernizante se desenvolve na orla da cidade média de Marabá por meio de iniciativas voltadas para a geração de energia, a criação de um corredor centro-norte de transporte fluvial de produtos e insumos e melhorias urbanas dedicadas especialmente a potencializar o espaço de waterfront fluvial para o comércio e o turismo, sobretudo em âmbito regional. Tal dinâmica intervém direta e indiretamente na produção do espaço da orla e em seus planos e dimensões desencontradas da consciência e da prática, que se manifestam por meio do percebido (práticas espaciais), do concebido (representações do espaço) e do vivido (espaços de representação) (Martins, 2008).

5 É importante destacar que não é pela identificação de fixos modernos (grandes armazéns, complexos de exposições e de grandes feiras, loteamentos de luxo, condomínios ecológicos e exclusivos, edifícios empresariais tecnológicos, hotéis de maior porte e com diversos serviços, grandes lojas de marcas internacionais etc.) que se constata uma tendência de apropriação do espaço de ribeira voltada principalmente para seu uso econômico (comercial, industrial ou turístico), mas pela difusão de uma urbanização empreendedora e com modificações menos chamativas e arrojadas do ponto de vista arquitetônico moderno, bem como por ações do poder público (em diferentes escalas) que procuram aproveitar seu potencial para o turismo, o transporte fluvial de maior porte ou a geração de energia hidrelétrica. Ademais, a análise do processo que transcorre na ribeira de Marabá mostra que a coalizão entre forças empreendedoras locais (comerciantes, proprietários fundiários, promotores imobiliários e grandes empresas) e o governo municipal pretendem torná-la mais visível e competitiva na escala regional e mesmo nacional do que propriamente na escala internacional (Lima, 2013). 
Assim, é no momento de ascensão e de dominação do espaço abstrato ${ }^{6}$ em relação ao espaço diferencial ${ }^{7}$ existente na orla da cidade de Marabá que se instaura a contradição entre o consumo produtivo (de toda sorte de mais valia) do espaço e o seu consumo improdutivo (o prazer, o gozo, a obra). Isto é, entre os utilizadores capitalistas e os usuários pertencentes à coletividade e a outras dinâmicas, tempos e ritmos sociais que não tem como maior referencial de vida o lucro e a produção de mais valia; usuários para os quais o espaço é vivido, e não apenas reconhecido pelo olhar (percebido) ou representado (concebido) (Lefebvre, 1974).

Acentua-se, então, os conflitos entre a dimensão do vivido, que é o espaço da representação, que se vive e se fala, das necessidades reais, do núcleo ou centro afetivo, dos lugares da paixão e da ação, das situações sentidas (vivenciadas), do simbólico, da arte e do lado clandestino e subterrâneo da vida social, com a dimensão do percebido (base prática de percepção do mundo exterior, da coesão, do que está posto e é identificável, do visível) e a dimensão do concebido (aquela que está ligada às relações de produção dominante, aos seus conhecimentos, aos seus signos, aos seus códigos, aos seus cientistas, aos seus planificadores, aos seus urbanistas, aos seus tecnocratas, aos seus retalhadores e agenciadores da realidade social etc.) (Lefebvre, 1974).

É com base nesse conflito entre as dimensões desencontradas da consciência e da prática social que a última seção deste trabalho mostra, pela identificação mais pontual dos diversos espaços de vivência e de identidade ribeirinha (Silva; Malheiro, 2005) de Marabá, que a dimensão do vivido ligada aos rios e à floresta não desaparece em face da ascensão do percebido e do concebido, mas sim se perpetua na ribeira marabaense principalmente por meio da formação de espaços de resistência e de disseminação e/ou difusão desses conteúdos socioespaciais ribeirinhos.

Os espaços de vivência e de identidade ribeirinha, categoria analítica com que Silva e Malheiro (2005) interpretaram as faces ribeirinhas da cidade de Belém do Pará por meio de sua orla fluvial, são os que: (a) estão à beira-rio, muito embora essa condição não defina automaticamente seu conteúdo socioespacial; (b) ligam-se à dinâmica da natureza (rio e floresta), pois o regime de cheias dos rios é muito importante para as atividades de cultivo, extração e pesca; (c) se configuram por meio de um arranjo de objetos espaciais/geográficos que se remetem ao "mundo das águas" (pequenos e pouco modernos portos, trapiches, barcos, canoas, rabetas etc.); (d) alocam atividades cotidianas que conformam um referencial de vida e, por conta disso, acabam compreendendo uma dimensão simbólica; (e) têm uma economia pouco dinâmica, menos capitalizada, mas de muita interação social; e (f) são permeados pelo desenvolvimento de interações com diversos grupos e por sobrevivências.

Tais espaços de vivências, de pescadores, de agricultores, de oleiros, de pedreiros, de carpinteiros, de barqueiros etc., em Marabá (Quadro 1), são permeados por objetos-símbolo ribeirinhos, assim como por uma diversidade de práticas sociais cotidianamente desenvolvidas e que estão ligadas a uma temporalidade lenta, fortemente marcada pela dinâmica dos rios e da natureza e onde as relações mais orgânicas e horizontais se realizam frequentemente (Lima; Nunes, 2011).

6 Espaço abstrato é aquele produzido pelo e para o capitalismo. É o espaço dominante, dos centros de riqueza e de poder que, ligado a grandes grupos econômicos pela troca (de bens e de mercadorias ou de palavras escritas ou faladas), implica o consenso social. Funciona "objetivamente" como um conjunto de coisas (signos e suas relações formais). Formal e quantificado, nega as diferenças que provêm da natureza e do tempo (histórico), assim como as oriundas de corpo, idade, sexo ou etnias (Lefebvre, 1974).

7 Espaço da reunião na diferença, da assunção da alteridade, da liberdade e do prazer, ele reúne os elementos dispersos e separados pelo espaço abstrato e pelas ideologias que os justificam. Assim, considera indissociáveis o micro e o macro, o cotidiano e o urbano, o interior e o exterior, o trabalho e o não trabalho (o consumo improdutivo, o prazer, a festa), o durável e o efêmero etc. (Lefebvre, 1974). 


\section{(rios Tocantins e Itacaiunas)}

\begin{tabular}{|c|c|c|c|}
\hline espaço & rio & principais identificadores da paisagem & principais usos e funções \\
\hline $\begin{array}{c}\text { bairro } \\
\text { Cabelo Seco }\end{array}$ & $\begin{array}{l}\text { encontro dos } \\
\text { Rios Tocantins e } \\
\text { Itacaiunas }\end{array}$ & $\begin{array}{l}\text { Pequenas e modestas casas de madeira; acesso } \\
\text { de terra aos rios; roupas estendidas em varais } \\
\text { nas ruas, nas varandas ou nos telhados das } \\
\text { casas; canoas e rabetas à beira-rio; homens e } \\
\text { mulheres com a pele queimada de sol saindo ou } \\
\text { chegando da pesca ou do trabalho; moradores } \\
\text { na frente ou no quintal das casas conversando; } \\
\text { crianças brincando na ribeira; pesca em grande } \\
\text { parte para subsistência e como atividade com- } \\
\text { plementar à renda; infraestrutura precária. }\end{array}$ & $\begin{array}{l}\text { Moradia; atividade portuária } \\
\text { de pequena escala; lazer no } \\
\text { rio e na orla; uso doméstico } \\
\text { do espaço da orla e da água } \\
\text { do rio; transmissão aos mais } \\
\text { novos do saber relativo à dinâ- } \\
\text { mica dos rios e da natureza. }\end{array}$ \\
\hline $\begin{array}{l}\text { rampa da } \\
\text { orla Sebastião } \\
\text { Miranda }\end{array}$ & rio Tocantins & $\begin{array}{l}\text { Rampa com acesso ao rio; tábuas de madeira } \\
\text { dentro do rio para lavagem de roupas e louça; } \\
\text { canoas, rabetas, jet skis e casas flutuantes apor- } \\
\text { tadas ao redor da rampa; equipamentos de lazer. }\end{array}$ & $\begin{array}{l}\text { Atividade portuária de pe- } \\
\text { quena escala; lazer no rio e na } \\
\text { orla; uso doméstico da água } \\
\text { do rio. }\end{array}$ \\
\hline
\end{tabular}

Pequenas e modestas casas de madeira ou alvenaria; rampa com acesso ao rio; tábuas de madeira dentro do rio para lavar roupas e louça; canoas e rabetas justapostas e aportadas ao lote da Rampa rio Tocantins redor da rampa; roupas estendidas em varais; redes nas varandas e salas das casas; cadeiras na frente das casas; bares e restaurantes; pescadores nas ruas e na beira-rio; abrigos para as canoas feitas de madeira e palha.

Moradia; atividade portuária de pequena escala; lazer na orla e no rio; uso doméstico do espaço da orla e da água do rio.

Casas modestas de madeira com portas e janelas abertas para a rua; acesso de terra ao rio Itacaiunas; tábuas de madeira dentro do rio para Porto das Canoinhas rio Itacaiunas lavar roupas e louça; redes nas salas e varandas das casas; canoas e rabetas aportadas à beira-rio; movimento de moradores e pescadores; infraestrutura precária.

Canoas e rabetas aportadas à beira-rio; acesso de terra ao rio Itacaiunas; casas modestas de Amapazinho rio Itacaiunas alvenaria; moradores conversando nas ruas e em frente às casas; homens saindo ou chegando da pesca; infraestrutura precária.
Moradia; atividade portuária de pequena escala; lazer na orla e no rio; uso doméstico da orla e da água do rio.
Uso doméstico da água do rio; atividade portuária de pequena escala; moradia.
Tábuas de madeira dentro do rio para lavar roupas e louça; acesso de terra ao rio Tocantins; casas modestas em alvenaria; crianças brincando na ribeira; infraestrutura precária.
Uso doméstico da água do rio; moradia; lazer no rio.

Moradia; lazer no rio e na orla; atividades portuárias de pequena escala; comércio de bebida e comida; intenso uso doméstico da água do rio; maior transmissão aos mais novos do saber relativo à dinâmica dos rios e da natureza; transmissão da arte de confecção e de reparo de canoas e rabetas. 


\begin{tabular}{|c|c|c|c|}
\hline $\begin{array}{c}\text { rampa do bairro } \\
\text { Santa Rosa }\end{array}$ & rio Tocantins & $\begin{array}{l}\text { Canoas e rabetas aportadas justapostas; abrigos } \\
\text { feitos em madeira e palha para as tábuas (que } \\
\text { servem de ponte) e as canoas; refrigeradores e } \\
\text { isopores para os pescados; rampa em alvenaria } \\
\text { de acesso ao rio; carros e caminhões estacio- } \\
\text { nados; intenso fluxo de pessoas para comprar } \\
\text { e vender pescado; colônia de pescadores Z30 e } \\
\text { fábrica de gelo. }\end{array}$ & $\begin{array}{l}\text { Comércio do pescado; lazer } \\
\text { no rio; atividade portuária e } \\
\text { pesqueira. }\end{array}$ \\
\hline $\begin{array}{l}\text { comunidade do } \\
\text { Geladinho }\end{array}$ & rio Tocantins & $\begin{array}{l}\text { Canoas e rabetas justapostas aportadas na } \\
\text { ribeira; acesso de terra ao rio Tocantins; bares } \\
\text { com mesas e cadeiras na ribeira; abrigos feitos } \\
\text { de madeira e palha para canoas, barcos e } \\
\text { utensílios pesqueiros e domésticos; palafitas; } \\
\text { movimento de pescadores e moradores; tábuas } \\
\text { de madeira dentro do rio para lavar roupas e } \\
\text { louça; crianças brincando na ribeira; pesca em } \\
\text { grande parte para subsistência e como atividade } \\
\text { complementar à renda; infraestrutura precária. }\end{array}$ & $\begin{array}{l}\text { Moradia; lazer no rio e na } \\
\text { orla; atividades portuárias de } \\
\text { pequena escala; comércio de } \\
\text { bebida e comida; uso domés- } \\
\text { tico da água do rio; maior } \\
\text { transmissão aos mais novos } \\
\text { do saber relativo à dinâmica } \\
\text { dos rios e da natureza. }\end{array}$ \\
\hline $\begin{array}{c}\text { rampa do São } \\
\text { Félix }\end{array}$ & rio Tocantins & $\begin{array}{l}\text { "Praia" (barra arenosa); palafitas; bares; rampa } \\
\text { em alvenaria com acesso ao rio; canoas e } \\
\text { rabetas aportadas justapostas; movimento de } \\
\text { pescadores; tábuas de madeira dentro do rio } \\
\text { para lavar roupas e louça; redes de pesca nas } \\
\text { varandas e na frente das casas; movimento de } \\
\text { moradores e pescadores; crianças brincando na } \\
\text { ribeira; infraestrutura precária. }\end{array}$ & $\begin{array}{l}\text { Moradia; lazer no rio; ativi- } \\
\text { dades portuárias de pequena } \\
\text { escala; uso doméstico da água } \\
\text { do rio. }\end{array}$ \\
\hline $\begin{array}{l}\text { Vila Espírito } \\
\text { Santo }\end{array}$ & rio Tocantins & $\begin{array}{l}\text { Alguns bares; canos e rabetas aportadas } \\
\text { justapostas; intenso movimento de pescadores; } \\
\text { pesca em grande parte para subsistência e como } \\
\text { atividade complementar à renda; casas de palha, } \\
\text { alvenaria e madeira; transporte de pessoas para } \\
\text { os bancos de areia do Tocantins e para as comu- } \\
\text { nidades ao longo do rio; lavagem de roupa e } \\
\text { louça na beira-rio; infraestrutura precária. }\end{array}$ & $\begin{array}{l}\text { Moradia; comércio de comida } \\
\text { e bebida; lazer no rio; ativi- } \\
\text { dades portuárias de pequena } \\
\text { escala; uso doméstico da água } \\
\text { do rio; transmissão aos mais } \\
\text { novos do saber relativo aos } \\
\text { rios e à natureza. }\end{array}$ \\
\hline Porto do Tacho & rio Itacaiunas & $\begin{array}{l}\text { Alguns bares; canos e rabetas aportadas de } \\
\text { forma justaposta; intenso movimento de pesca- } \\
\text { dores; pesca em grande parte para subsistência } \\
\text { e como atividade complementar à renda; casas } \\
\text { de alvenaria e madeira; intenso transporte de } \\
\text { pessoas para os bancos de areia do Itacaiunas e } \\
\text { para as comunidades ao longo do rio; lavagem } \\
\text { de roupas e louça na beira-rio; crianças brincan- } \\
\text { do na ribeira; infraestrutura precária. }\end{array}$ & $\begin{array}{l}\text { Moradia; comércio de comi- } \\
\text { das e bebidas; lazer no rio; ati- } \\
\text { vidades portuárias de pequena } \\
\text { escala; uso doméstico da água } \\
\text { do rio. }\end{array}$ \\
\hline $\begin{array}{l}\text { balneário } \\
\text { Vavazão }\end{array}$ & rio Itacaiunas & $\begin{array}{l}\text { Alguns bares; canos e rabetas aportadas de } \\
\text { forma justaposta; movimento de pescadores; } \\
\text { pesca em grande parte para subsistência e como } \\
\text { atividade complementar à renda; casas de palha, } \\
\text { alvenaria e madeira; escada de madeira que dá } \\
\text { acesso ao rio; intenso transporte de pessoas } \\
\text { para os bancos de areia do Itacaiunas e para as } \\
\text { comunidades ao longo do rio; lavagem de roupa } \\
\text { e louça na beira-rio; crianças brincando na } \\
\text { ribeira; infraestrutura precária. }\end{array}$ & $\begin{array}{l}\text { Moradia; comércio de comi- } \\
\text { das e bebidas; lazer no rio; ati- } \\
\text { vidades portuárias de pequena } \\
\text { escala; uso doméstico da água } \\
\text { do rio. }\end{array}$ \\
\hline
\end{tabular}

fonte: Levantamento de campo realizado em outubro/novembro de 2010 e em dezembro de 2012. elaboração: Michel de Melo Lima e Débora Aquino Nunes. 
Os espaços de identidade e de vivência ribeirinha de Marabá dispõem de uma morfologia material e social conforma e dá corpo a verdadeiras "trincheiras de resistência" (Oliveira, 2010) à tentativa de totalização operada pelo binômio técnica-mercadoria e o seu equivalente, o valor de troca. São formados por agentes/grupos sociais ligados às águas dos rios Tocantins e Itacaiunas (econômica, funcional e culturalmente), que (co)existem, na diferença e na desigualdade, com os demais agentes/grupos sociais que se apropriam da orla no contexto atual, como o Estado, os comerciantes locais e regionais, as grandes empresas, os turistas etc. Tal situação evoca a necessidade de superação plena da dicotomia água-urbe para que se reconheça as especificidades do urbano e se alcance o direito à cidade (Lefebvre, 2006) em Marabá.

$\bigcirc$ direito à cidade se manifesta como a forma superior dos direitos, sendo condição para a realização de todos os outros. É o direito à liberdade, à repetição, à criação, à individualização na socialização. É o direito ao habitat e ao habitar, é o direito à cidade como obra (à atividade participante) e o direito à apropriação (o que é diferente do direito à propriedade) (Lefebvre, 2006) que daria aos agentes/grupos ligados ao vivido ribeirinho maiores possibilidades de reprodução social. Portanto, é o que permitiria o exercício da cidadania plena e mais igualitária a seus agentes/grupos que constituem e produzem o espaço de orla (moradores, pescadores, agricultores, oleiros, pedreiros, carpinteiros, barqueiros, comerciantes etc.), assim como o atendimento de suas demandas, ensejando mais justiça social, sobretudo em âmbito local.

\section{Considerações finais}

Considerar a dimensão ribeirinha da orla e do cotidiano de Marabá - uma cidade extremamente modificada por sua atual dinâmica econômica e pelos processos modernizantes que se desenvolvem em seu espaço urbano - implica reconhecer a existência de diferentes temporalidades e espacialidades que acabam por definir seus ritmos, sua alteridade e sua diferença no contexto urbano amazônico.

Além disso, é importante frisar que, na orla de Marabá, a dimensão ribeirinha que resiste ao processo de modernização empreendedora é cada vez mais sufocada por uma lógica capitalista mercadófila e homogeneizante. Isso confirma a importância do reconhecimento das diferenças e do direito à cidade como estratégia e possibilidade de viver o urbano (multiplicidade de trajetórias, ritmos e tempos desencontrados e desiguais) na Amazônia.

É também uma condição sine qua non para a reprodução desses agentes/grupos no espaço de orla (pescadores, oleiros, pedreiros etc.), uma maior organização política e mais consciência de seu protagonismo social no âmbito da ribeira marabaense, o que até agora é muito tímido, quase inexistente (Lima, 2013).

Assim, é preciso desenvolver um movimento político em diferentes escalas (regional, nacional e internacional), capaz de reunir de modo apropriado a multiplicidade de descontentes gerada pelo exercício (simulado ou não) do interesse e do poder burguês em busca de um neoliberalismo utópico (Harvey, 2012). Trata-se de criar organizações, instituições, doutrinas, programas, estruturas formais ou não etc. que operem e desenvolvam ações em favor de algum propósito em comum: a superação das contradições engendradas pela reprodução do capital, seja no âmbito da fábrica ou no próprio espaço. De uma atividade política que estaria firmemente assentada nas condições históricas e geográficas concretas em cujo âmbito 
se desenrola a ação humana. Um movimento aberto (formado por instituições, pela classe trabalhadora, pelos mais diferentes movimentos sociais etc.) e articulado em diferentes escalas que, estendendo-se pelo espaço e pelo tempo, possa enfrentar as qualidades e as estratégias universais e transnacionais da acumulação de capital.

\section{Referências}

ALMEIDA, J. J. A cidade de Marabá sob o impacto dos projetos governamentais.

Dissertação (Mestrado em História Econômica) - Faculdade de Filosofia, Letras e Ciências Humanas, Universidade de São Paulo, São Paulo, 2008.

CORREAA, R. L. A periodização da rede urbana da Amazônia. Revista Brasileira de Geografia, Rio de Janeiro, v. 49, n. 3, p. 39-68, jul./set. 1987.

DIAS, C. V. Marabá: centro comercial da castanha. Revista Brasileira de Geografia, Rio de Janeiro, v. 20, n. 4, p. 383-425, 1958.

EMMI, M. F. A oligarquia do Tocantins e o domínio dos castanhais. 2. ed. Belém: Naea-UFPA, 1999.

HARVEY, D. Espaços de esperança. 5. ed. São Paulo: Loyola, 2012.

A produção capitalista do espaço. São Paulo: Annablume, 2005.

LEFEBVRE, H. O direito à cidade. 4. ed. São Paulo: Centauro, 2006.

La production de l'espace. Paris: Anthropos, 1974.

LIMA, M. M. A ribeira $\mathcal{E}$ a orla: espacialidades e territorialidades urbanas ribeirinhas em uma cidade amazônica em transformação. Dissertação (Mestrado em geografia) - Instituto de Filosofia e Ciências Humanas, Universidade Federal do Pará, Belém, 2013.

; NUNES. D. A. A ão cidade-rio na Amazônia: espacialidades e territorialidades no espaço da orla fluvial de Marabá-Pa. In: SIMPÓSIO NACIONAL DE GEOGRAFIA URBANA, 12., 2011, Belo Horizonte. Anais..., Belo Horizonte, 2011. CD-Rom.

NASSER, A. C. A.; FUMAGALLI, M. A opressão da equivalência, as diferenças. In: MARTINS, J. S. (Org.). Henri Lefebvre e o retorno a dialética. São Paulo: Hucitec, 1996, p. 25-37.

MARABÁ. Secretaria do Município de Marabá. Diagnóstico do Plano Diretor urbano de Marabá. Marabá, 2006.

MARIN, R. E. A.; TRINDADE, J. Wakymãhã mekto kônhito-nxàkaka: Projeto da Hidrelétrica de Marabá-Pará. In: ALMEIDA, A. W. B. (Org.). Conflitos sociais no Complexo Madeira. Manaus: Projeto Nova Cartografia Social da Amazônia/UEA Edições, 2009. p. 367-389.

MARTINS, J. S. A sociedade vista do abismo: novos estudos sobre exclusão, pobreza e classes sociais. 3. ed. Rio de Janeiro: Vozes, 2008. 
MATTOS, M. V. B. História de Marabá. Marabá: Grafil, 1996.

OLIVEIRA, M. P. A utopia do direito à cidade: possibilidades de superação da dicotomia favela-bairro no Rio de Janeiro. In: OLIVEIRA, J. A. (Org.). Cidades brasileiras: territorialidades, sustentabilidade e demandas sociais. Manaus: Edua, 2010. p. 288-302.

ROCHA, G. M. Todos convergem para o lago! Hidrelétrica de Tucuruí: municípios e territórios na Amazônia. Belém: Numa-UFPA, 2008.

SILVA, M. A. P.; MALHEIRO, B. C. P. Faces ribeirinhas da orla fluvial de Belém: espaços de (sobre)vivência na diferença. In: TRINDADE JR., S.-C.; SILVA, M. A. P. (Org.). Belém: a cidade e o rio na Amazônia. Belém: Edufpa, 2005. p.145-169.

TAVARES, M. G. A dinâmica espacial da rede de distribuição de energia elétrica no estado do Pará (1960-1996). Tese (Doutorado em Geografia) - Universidade Federal do Rio de Janeiro, Rio de Janeiro, 1999.

TOCANTINS, L. O rio comanda a vida: uma interpretação da Amazônia. 2. ed. Rio de Janeiro: Civilização Brasileira, 1961.

TRINDADE JR., S.-C. C. Cidades médias na Amazônia oriental: das novas centralidades à fragmentação dos territórios. In: Encontro da Associação Nacional de Pós-graduação e Pesquisa em Planejamento Urbano e Regional, 14., 2011, Rio de Janeiro. Anais... Rio de Janeiro, 2011. CD-Rom.

. Diferenciação territorial e urbanodiversidade: elementos para pensar uma agenda urbana em nível nacional. Cidades, Presidente Prudente: Grupo de Estudos Urbanos, v. 7, n. 12, p. 49-77, jul./dez. 2010.

TRINDADE JR., S.-C. C.; AMARAL, M. D. B.; SILVA, M. A. P. Das “janelas" às "portas" para os rios: compreendendo as cidades ribeirinhas na Amazônia. In: TRINDADE JR., S.-C.; TAVARES, M. G. (Org.). Cidades ribeirinhas na Amazônia: mudanças e permanências. Belém: Edufpa, 2008. p. 27-47.

TRINDADE JR., S.-C. C.; SANTOS, E. R. C.; RAVENA, N. A cidade e o rio: espaço e tempo na orla fluvial de Belém. In: TRINDADE JR., S.-C. C.; SILVA, M. A. P. (Org.). Belém: a cidade e o rio na Amazônia. Belém: Edufpa, 2005. p. 12-43.

VELHO, O. G. Frentes de expansão e estrutura agrária: estudo do processo de penetração numa área da Tranzamazônica. Rio de Janeiro: Zahar, 1972.

YOSCHIOKA, H. Avaliação de implantação de um núcleo urbano em área na Amazônia: o exemplo de Nova Marabá, Pará. Dissertação (Mestrado em Geografia) - Faculdade de Filosofia, Letras e Ciências Humanas, Universidade de São Paulo, São Paulo, 1986. 